\title{
PERTUMBUHAN DAN HASIL KACANG HIJAU DARI BERBAGAI POPULASI DENGAN MULSA ORGANIK
}

\author{
Amalia Dita Riyaningsih ${ }^{1)}$, Supriyono ${ }^{\left.2^{*}\right)}$, Jauhari Syamsiyah ${ }^{2)}$ \\ 1) Mahasiswa Program Studi Agroteknologi Fakultas Pertanian UNS Surakarta \\ 2) Staf Pengajar Program Studi Agroteknologi Fakultas Pertanian UNS Surakarta \\ Author Contact: supriyono_uns@yahoo.com
}

\begin{abstract}
Mung beans are one of the common beans comodities consumed after soybeans and peanuts. The national mung beans production was 0.7 tons in average, which is lower than the potential yield. Production of mung bean can be improved by modifying the microclimate by mulching and regulating crop density. The purpose of this research was to improve the yield of mungbean. Research method used was Completely Randomized Design (CRD). The treatments were organic mulching of mahagony leaves, straws, husks, and without mulch (M1, M2, M3, M0) and the crops density 1 and 2 crops (B1 and B2). The results showed interaction between organic mulches and crops density significantly affected the crops' height and number of productive branches. Interaction of straw mulches and two crops density increased the crops' height $37,91 \%$ than the control and has the most productive branches. Organic mulches significantly affected to flowering period and number of hardseeds. Husk mulches accelerated flowering period and decrease the number of hardseeds. Organic mulch and number of crop's density treatments has not to improve the yield of mungbean yet. The yield of mungbean can achieved in this research was 1,54 ton $\mathrm{ha}^{-1}$.
\end{abstract}

Keywords: Vima-1, Soil Temperature, Competition

\section{AGROTECHNOLOGY RESEARCH JOURNAL}

Riyaningsih AD, Supriyono, Syamsiyah J. 2018. Pertumbuhan dan hasil kacang hijau dari berbagai populasi dengan mulsa organik. Agrotech Res J 2(2): 58-62.

Riyaningsih AD, Supriyono, Syamsiyah J. 2018. Growth and yield of mung bean by different density and organic mulches. Agrotech Res J 2(2): 58-62.

\section{PENDAHULUAN}

Kacang hijau (Vigna radiata) adalah komoditas tanaman kacang-kacangan yang dikonsumsi oleh masyarakat dan menempati urutan ketiga setelah kedelai dan kacang tanah. Menurut Iswanto (2017) kacang hijau memiliki potensi tinggi untuk dikembangkan karena memiliki beberapa kelebihan yaitu berumur genjah (55-65 hari), toleran terhadap kekeringan, dan dapat ditanam di daerah kurang subur.

Permasalahan dalam budidaya tanaman kacang hijau pada tingkat petani yaitu hasil rendah. Hal ini terjadi akibat teknik budidaya kurang maksimal. Ratarata hasil kacang hijau tingkat nasional sekitar 0,9 ton ha $^{-1}$ (Balitkabi 2012) jauh lebih rendah dari potensi hasil yang mencapai 1,6 ton ha ${ }^{-1}$. Jika kacang hijau dikembangkan dengan teknik budidaya yang tepat maka hasil dapat mencapai 2,0 ton ha ${ }^{-1}$ (Balitkabi 2010). Peningkatan hasil kacang hijau perlu dilakukan dengan inovasi dalam teknik budidaya salah satu adalah menggunakan mulsa organik dan pengaturan jumlah tanaman per lubang tanam.

Mulsa memiliki manfaat menjaga kestabilan suhu dalam tanah, menjaga kelembaban tanah, mengurangi energy air yang jatuh ke permukaan tanah secara langsung sehingga memperkecil pelindian hara, erosi serta dapat menyumbang bahan organik sehingga meningkatkan kesuburan tanah (Sunghening 2012). Penelitian ini menggunakan mulsa organik dari jerami, sekam, dan seresah tanaman. Mulsa organik digunakan karena mudah didapat dengan jumlah banyak dan biaya murah.
Jumlah tanaman per lubang tanam berfungsi untuk menentukan populasi tanaman per satuan luas. Populasi tanaman berkaitan dengan kerapatan populasi yang akan mempengaruhi hasil tanaman kacang hijau. Hal ini terkait dengan kompetisi antar tanaman dalam memperoleh cahaya, air, ruang, serta unsur hara (Susilo et al. 2015). Jumlah tanaman mempengaruhi kedalaman akar dan luas jangkauan akar. Jumlah tanaman adalah salah satu langkah yang untuk mencapai hasil panen yang tinggi per satuan luas tertentu dalam budidaya. Tujuan penelitian ini adalah mempelajari interaksi antara mulsa organik dan populasi tanaman pada pertumbuhan dan hasil kacang hijau.

\section{METODE PENELITIAN}

Penelitian dilaksanakan bulan Oktober sampai Desember 2017 di Lahan Percobaan Fakultas Pertanian Universitas Sebelas Maret Surakarta, Desa Sukosari, Kecamatan Jumantono, Karanganyar. Lokasi

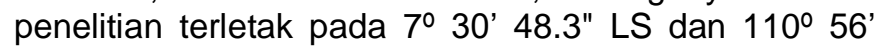
51.2" BT dengan ketinggian 170 mdpl dan menggunakan jenis tanah alfisol. Penelitian menggunakan RAL (Rancangan Acak Lengkap) yang terdiri dari dua faktor. Faktor pertama pemberian mulsa organik terdiri dari serasah mahoni (M1), jerami (M2), sekam (M3) dan tanpa mulsa (M0). Faktor kedua jumlah populasi tanaman terdiri dari 1 tanaman (B1) dan 2 tanaman (B2). Data penelitian dianalisis menggunakan analisis ragam atau ANOVA (Analysis of Variance) berdasarkan uji $\mathrm{F} 5 \%$ dan uji beda nyata 
dengan DMRT (Duncan's Multiple Range Test) dengan taraf $5 \%$.

\section{HASIL DAN PEMBAHASAN}

Kacang hijau memberikan respon pertumbuhan yang berbeda-beda terhadap pemberian mulsa organik dan jumlah populasi. Grafik laju pertumbuhan tanaman kacang hijau dengan pemberian mulsa organik dan jumlah populasi dapat dilihat pada Gambar 1.

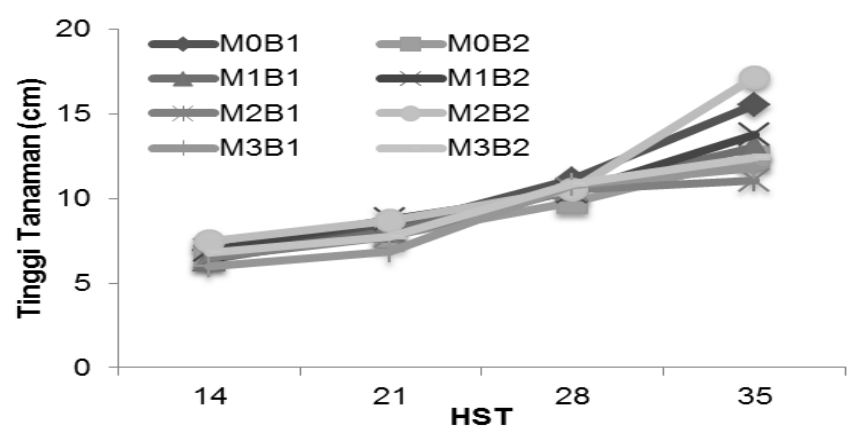

Keterangan:

M0B1 = Tanpa Mulsa dan Satu Tanaman

MOB2 = Tanpa Mulsa dan Dua Tanaman

M1B1 = Mulsa Mahoni dan Satu Tanaman

M1B2 = Mulsa Mahoni dan Dua Tanaman

M2B1 = Mulsa Jerami dan Satu Tanaman

M2B2 = Mulsa Jerami dan Dua Tanaman

M3B1 = Mulsa Sekam dan Satu Tanaman

M3B2 = Mulsa Sekam dan Dua Tanaman

Gambar 1 Grafik laju partumbuhan kacang hijau perlakuan mulsa organik dan jumlah populasi tanaman
Rata-rata pertumbuhan mengalami peningkatan nyata pada 28 hari setelah tanam. Pertumbuhan kacang hijau menunjukkan bahwa penggunaan mulsa jerami pada dua tanaman per lubang meningkatkan pertumbuhan (tinggi) secara signifikan. Tanaman tertinggi $(17,15 \mathrm{~cm})$ dicapai oleh 2 tanaman per lubang dengan mulsa jerami. Kacang hijau 1 dan 2 tanaman per lubang mencapai tinggi hampir sama jika menggunakan mulsa serasah mahoni dan sekam, namun penggunaan mulsa jerami menyebabkan perbedaan tinggi sebesar $6,10 \mathrm{~cm}$ pada 2 tanaman. Pertumbuhan yang siginifikan disebabkan oleh pemberian mulsa jerami yang mampu mengontrol suhu tanah. Suhu tanah pada mulsa jerami kedalaman lebih dari $5 \mathrm{~cm}$ memiliki suhu lebih rendah dari tanah tanpa mulsa (Midmore 1983). Penelitian kacang hijau ini menggunakan mulsa jerami dengan ketebalan rata-rata $4,5 \mathrm{~cm}$ dan mampu menurunkan suhu tanah sebesar $1^{\circ} \mathrm{C}$ dari kontrol. Suhu tanah sangat mempengaruhi proses metabolisme pada tanaman seperti fotosintesis dan respirasi. Mulsa jerami memiliki daya hantar panas yang rendah (Hamdani 2009) sehingga panas yang sampai di permukaan tanah lebih sedikit dan tetap stabil sehingga proses fotosintesis dapat berlangsung secara optimum dan fotosintat dapat digunakan untuk tumbuh. Menurut Karamina et al. (2017) suhu tanah yang optimal untuk aktivitas mikrobia adalah $18-30^{\circ} \mathrm{C}$. Penurunan suhu di permukaan tanah juga dibantu oleh tajuk tanaman yang saling menaungi pada M2B2 sehingga cahaya matahari lebih terserap optimal didaun daripada ke permukaan tanah.

Tabel 1 Interaksi mulsa organik dan jumlah populasi terhadap tinggi tanaman, jumlah cabang produktif, berat segar brangkasan, berat kering brangkasan, jumlah polong, berat 100 biji, jumlah biji, berat biji, dan suhu tanah

\begin{tabular}{lcccccccc}
\hline \multirow{2}{*}{ Variabel Pengamatan } & \multicolumn{7}{c}{ Perlakuan } \\
\cline { 2 - 8 } & M0B1 & M0B2 & M1B1 & M1B2 & M2B1 & M2B2 & M3B1 & M3B2 \\
\hline Tinggi Tanaman (cm) & $15,52 \mathrm{bc}$ & $12,42 \mathrm{a}$ & $13,02 \mathrm{ab}$ & $13,82 \mathrm{ab}$ & $11,05 \mathrm{a}$ & $17,15 \mathrm{c}$ & $11,77 \mathrm{a}$ & $12,42 \mathrm{a}$ \\
Jumlah Cabang Produktif & $15,75 \mathrm{ab}$ & $10,75 \mathrm{a}$ & $13,75 \mathrm{ab}$ & $19 \mathrm{abc}$ & $13,75 \mathrm{ab}$ & $24,25 \mathrm{c}$ & $13,25 \mathrm{ab}$ & $20,50 \mathrm{c}$ \\
(cabang) & & & & & & & & \\
Berat Segar Brangkasan & $32,13 \mathrm{ab}$ & $23,26 \mathrm{a}$ & $32,29 \mathrm{ab}$ & $41,72 \mathrm{ab}$ & $45,38 \mathrm{ab}$ & $41,93 \mathrm{ab}$ & $39,47 \mathrm{ab}$ & $51,38 \mathrm{~b}$ \\
(g) & & & & & & & & \\
Berat Kering Brangkasan & $7,34 \mathrm{a}$ & $6,02 \mathrm{a}$ & $7,03 \mathrm{a}$ & $10,33 \mathrm{a}$ & $10,32 \mathrm{a}$ & $11,47 \mathrm{a}$ & $8,81 \mathrm{a}$ & $12,75 \mathrm{a}$ \\
(g) & $26,00 \mathrm{ab}$ & $22,25 \mathrm{a}$ & $28,75 \mathrm{ab}$ & $31,25 \mathrm{ab}$ & $39,00 \mathrm{ab}$ & $46,25 \mathrm{~b}$ & $30,25 \mathrm{ab}$ & $30,75 \mathrm{ab}$ \\
Jumlah Polong (polong) & $232,75 \mathrm{a}$ & $187,75 \mathrm{a}$ & $255,75 \mathrm{a}$ & $279,75 \mathrm{a}$ & $341,00 \mathrm{a}$ & $322,25 \mathrm{a}$ & $283,25 \mathrm{a}$ & $269,50 \mathrm{a}$ \\
Jumlah Biji Total (butir) & $5,44 \mathrm{a}$ & $4,88 \mathrm{a}$ & $5,14 \mathrm{a}$ & $5,37 \mathrm{a}$ & $5,06 \mathrm{a}$ & $5,16 \mathrm{a}$ & $5,43 \mathrm{a}$ & $5,60 \mathrm{a}$ \\
Berat 100 Biji (g) & $11,76 \mathrm{a}$ & $8,48 \mathrm{a}$ & $12,40 \mathrm{a}$ & $14,05 \mathrm{a}$ & $15,43 \mathrm{a}$ & $17,02 \mathrm{a}$ & $12,7 \mathrm{a}$ & $13,67 \mathrm{a}$ \\
Berat Biji Total (gram) & $35,5 \mathrm{a}$ & $35,5 \mathrm{a}$ & $35,5 \mathrm{a}$ & $36,25 \mathrm{a}$ & $36,5 \mathrm{a}$ & $36,25 \mathrm{a}$ & $36,5 \mathrm{a}$ & $36,0 \mathrm{a}$ \\
\hline Suhu Tanah (을 & & & &
\end{tabular}

Keterangan: Angka yang diikuti dengan huruf yang sama tidak berbeda nyata pada DMRT taraf $5 \%$.

Cabang produktif tanaman kacang hijau sangat dipengaruhi oleh jumlah populasi tanaman, namun tidak dipengaruhi oleh pemberian mulsa (Tabel 2).

Tabel 2 Pengaruh jumlah populasi tanaman terhadap jumlah cabang produktif

\begin{tabular}{ccc}
\hline & Populasi tanaman & Jumlah cabang produktif \\
\hline 1 & 14,13
\end{tabular}

\begin{tabular}{|c|c|}
\hline Populasi tanaman & Jumlah cabang produktif \\
\hline 2 & 18,63 \\
\hline
\end{tabular}

Jumlah cabang produktif pada dua tanaman memiliki hasil lebih tinggi (18,63 cabang) dibandingkan pada satu tanaman (14,13 cabang). Interaksi antara mulsa organik dan jumlah populasi secara umum memiliki jumlah cabang yang lebih banyak 
dibandingkan dengan tanpa perlakuan. Tabel 1 menunjukkan bahwa perlakuan mulsa jerami dengan populasi 2 tanaman (M2B2) mampu meningkatkan jumlah cabang produktif yaitu rata-rata 24,25 cabang produktif dibandingkan kontrolnya 11 cabang. Semakin banyak cabang produktif menghasilkan semakin banyak polong per tanaman (Canci dan Toker 2014). Cabang produktif dipengaruhi oleh kompetisi tanaman terutama pada pengambilan faktor tumbuh. Menurut Gardner et al. (1991) kerapatan tanaman menyebabkan berkurangnya ketersediaan cahaya pada tajuk bagian bawah. Semakin banyak populasi tanaman dapat mengurangi pertumbuhan cabang sebab terjadi kompetisi syarat tumbuh seperti cahaya.

Waktu berbunga dipengaruhi oleh mulsa organik secara tunggal dan tidak dipengaruhi oleh jumlah populasi tanaman. Pemberian mulsa sekam mampu mempercepat proses pembungaan pada tanaman kacang hijau. Tabel 3 menunjukkan mulsa sekam berbunga rata-rata pada umur 33 HST sedangkan kontrol berbunga pada umur 34 HST. Permukaan mulsa sekam memiliki suhu yang lebih tinggi dibandingkan dengan mulsa lainnya. Menurut Modal et al. (2011) suhu merupakan faktor lingkungan utama yang menentukan pertumbuhan dan produksi kacang hijau. Fase pembungaan dan pengisian biji pada kacang hijau akan lebih cepat terjadi pada suhu udara yang lebih tinggi. Menurut Wiwara et al. (2013) sekam bersifat padat sehingga mampu mempertahankan suhu dan kelembaban tanah karena akumulasi panas yang segera ditranslokasikan ke udara. Mulsa sekam mampu mempertahankan panas lebih lama dibandingkan dengan mulsa lainnya, Hal ini menyebabkan kondisi disekitar tanaman menjadi lebih hangat. Suhu yang lebih tinggi disekitar tanaman mendukung proses inisiasi bunga (Salisbury 1963).

Berat segar menunjukkan banyaknya bahan yang dihasilkan tanaman selama pertumbuhan. Interkasi mulsa organik dengan jumlah populasi tanaman tidak mempengaruhi berat segar brangkasan tanaman kacang hijau. Tabel 1 menunjukkan rata-rata berat segar akibat perlakuan mulsa organik dan jumlah populasi tanaman berkisar 23,26-51, 383 gram. Berat segar dipengaruhi oleh faktor tumbuh serapan hara yang diserap tanaman. Pemberian mulsa dan pengaturan jumlah tanaman belum mampu mengoptimalkan serapan hara yang masuk ke tanaman. Menurut Febriyono et al. (2017) kompetisi antar tanaman dalam mendapatkan faktor pendukung pertumbuhan mempengaruhi pertumbuhan vegetatif tanaman. Faktor tumbuh yang diberlukan seperti cahaya, air dan unsur hara. Kurangnya air tanah menyebabkan perkembangan vegetatif tanaman berkurang (Bandani et al. 2014).

Tabel 3 Pengaruh mulsa organik terhadap waktu berbunga dan jumlah biji keras

\begin{tabular}{lcccc}
\hline \multirow{2}{*}{ Variabel Pengamatan } & \multicolumn{4}{c}{ Mulsa } \\
\cline { 2 - 5 } & Tanpa & Serasah Mahoni & Jerami & Sekam \\
\hline Waktu Berbunga (HST) & $34,00 \mathrm{ab}$ & $34,25 \mathrm{~b}$ & $34,75 \mathrm{~b}$ & $33,00 \mathrm{a}$ \\
Biji Keras (butir) & $30,88 \mathrm{a}$ & $42,50 \mathrm{a}$ & $64,50 \mathrm{~b}$ & $29,38 \mathrm{a}$ \\
\hline
\end{tabular}

Keterangan: Angka yang diikuti dengan huruf yang sama tidak berbeda nyata pada DMRT taraf $5 \%$.

Berat kering tanaman merupakan penimbunan dari asimilasi $\mathrm{CO}_{2}$ selama pertumbuhan yang disintesis tanaman dari senyawa anorganik pada proses fotosintesis. Tanaman kacang hijau yang diberi perlakuan mulsa organik dan jumlah populasi tanaman tidak mempengaruhi berat kering tanaman. Tabel 1 menunjukkan bahwa rata-rata berat kering dengan pemberian mulsa organik dan jumlah populasi tanaman berkisar 6,022-12,75 gram. perlakuan yang diberikan belum mampu meningkatkan berat kering tanaman sebab ketebalan mulsa belum efektif untuk mengendalikan lingkungan disekitar perakaran untuk mendukung ketersediaan hara. Penggunaan mulsa (Pandey et al. 2015) mendorong perkembangan akar dan meningkatkan akumulasi bahan kering tanaman. Menurut Altland et al. (2016) aplikasi mulsa sekam padi dengan ketebalan 1.3 hingga $2.5 \mathrm{~cm}$ mampu mengontrol pertumbuhan gulma. Pemberian mulsa sekam padi mampu meningkatkan lingkungan tumbuh tanaman seperti fluktuasi suhu dan melindungi permukaan tanah sehingga mendukung perkembangan akar untuk menyerap nutrisi dengan baik (Ramadiana 2011). Pemberian mulsa mengakibatkan kelembaban tanah

jumlah biji berkisar 187,75 - 341 butir. Hal ini disebabkan saat pengisian biji tidak dipengaruhi oleh kondisi fisik tanah namun lebih dipengaruhi oleh nutrisi yang dihasilkan dan persaingan untuk lebih tinggi dan serapan hara oleh tanaman lebih maksimal (Bunkar et al. 2013).

Pembentukan polong perlu didukung dengan kondisi lingkungan yang sesuai untuk mendapatkan hasil yang optimum. Kondisi lingkungan untuk membentuk polong tidak dipengaruhi oleh mulsa organik dan jumlah populasi tanaman. Tabel 1 menunjukkan bahwa ratarata jumlah polong pada kacang hijau yang diberi perlakuan mulsa organik dan jumlah populasi tanaman berkisar 22,25-46,25 polong. Jumlah polong tertinggi terdapat pada kombinasi perlakuan M2B2 yaitu 46,25 polong. Menurut Chaturverdi et al. (1980) pada fase pembentukan polong akan terjadi peningkatan net assimilation rate hingga kemampuan maksimal. Net assimilation rate akan turun setelah batas maksimal karena nitrogen pada bagian vegetatif didistribusikan untuk pembentukan polong yang mengakibatkan daun tanaman kacang hijau mengering.

Pembentukan biji dipengaruhi oleh faktor genetis dan kondisi lingkungan. Pemberian mulsa organik dan pengaturan jumlah populasi tanaman untuk memodifikasi iklim mikro tidak berpengaruh terhadap jumlah biji. Tabel 1 menunjukkan bahwa rata-rata mendapatkannya. Hasil tanaman dipengaruhi oleh kualitas benih (Zecchinelli 2009). Kualitas benih juga dipengaruhi oleh beberapa faktor seperti genetik dan lingkungan tumbuhnya tanaman. Menurut Barnard dan 
Calitz (2011) pada kondisi stress suhu dan kelembaban, kesuburan rendah dan populasi gulma tinggi menyebabkan kualitas dan kuantitas biji.

Biji kacang hijau yang terbentuk semua dalam kondisi yang baik, terdapat 2-3 persen biji keras dalam pembentukan biji kacang hijau. Benih keras memiliki bentuk yang lebih kecil dari ukuran normal, keras dan berwarna hitam dan merupakan biji yang tidak diinginkan. Biji keras dipengaruhi oleh mulsa organik secara tunggal. Tabel 3 menunjukkan bahwa mulsa jerami menghasilkan biji keras (hard seed) paling banyak dengan rata-rata 64,5 biji dan mulsa sekam menghasilkan jumlah biji terendah rata-rat 29,38 butir. Mulsa jerami menghasilkan biji keras terbanyak sebab memiliki suhu yang tinggi dengan curah hujan yang tinggi pula masa pembentukan biji. Menurut Pott et al. (1978) biji keras terjadi sebab kondisi lingkungan yang merugikan yaitu suhu tinggi dan hujan pada masa pasca pematangan dan sebelum panen. Menurut Sripadhet et al (2007) persentase biji keras ditentukan oleh kematangan fisiologis, kombinasi suhu dan kelembaban tinggi. Pendapat lain dari Wasala et al. (2011) bahwa biji keras tidak berkaitan dengan ukuran biji namun disebabkan karena kandungan pektin yang tinggi sehingga biji bersifat permeabel.

Benih yang memiliki mutu baik biasanya memiliki ukuran dan bobot yang tinggi. Berat 100 biji memiliki variasi yang sangat rendah dan lebih ditentukan oleh genetik tanaman (Suprapto 2007). Berat biji tidak dipengaruhi oleh mulsa organik dan jumlah populasi tanaman serta interaksinya. Tabel 1 menunjukkan ratarata berat 100 biji pada kacang hijau dengan pemberian mulsa organik dan jumlah populasi tanaman memiliki rata-rata berkisar 4,883 - 5,602 gram. Hasil ini lebih rendah dari berat 100 biji pada deskripsi varietas dengan berat sebesar 6,3 gram. Ukuran benih menurut Rahmianna et al. (2015) merupakan faktor penting karena dianggap sebagai cerminan besarnya kandungan cadangan makanan benih tersebut. Waktu pengisian biji merupakan saat yang penting untuk mengetahui kualitas biji. waktu pengisian biji yang pendek menyebabkan pengisian cadangan makanan ke dalam biji terganggu. Cadangan makan masuk ke dalam biji dengan menggantikan kandungan air dari sel yang keluar sehingga bobot kering biji meningkat dan kandungan air biji menurun.

Berat biji akan mempengaruhi potensi hasil dari kacang hijau. Biji dengan kualitas yang baik memiliki cadangan makanan yang maksimal. Berat biji pada penelitian ini tidak dipengaruhi oleh penggunaan mulsa organik dan jumlah populasi tanaman serta interaksinya. Tabel 1 menunjukkan rata-rata berat bij akibat pemberian mulsa organik dan jumlah populasi tanaman berkisar antara 8,485 - 17,015 gram. Hasil ini berbeda dengan deskripsi varietas yang memiliki potensi hasil sebesar 1,76 ton $\mathrm{ha}^{-1}$. Hasil tertinggi yang dicapai pada penelitian ini sebanyak 1,54 ton $\mathrm{ha}^{-1}$. Faktor yang mempengaruhi kualitas biji yaitu hara, suhu, kelembaban tanah, dan cahaya (Rasyid 2013). Stres air selama pengisian biji (Kumar et al. 2018) menyebabkan menurunnya berat biji karena kurang nutrisi. Menurut Noorhadi dan Sudadi (2003) mulsa jerami memiliki sifat yang hampir sama dengan mulsa plastik yaitu mampu memantulkan panas, namun kelebihan dari jerami adalah meningkatkan penyerapan air sehingga panas yang dipantulkan lebih rendah.

Suhu merupakan salah satu faktor lingkungan yang sangat berpengaruh terhadap pertumbuhan dan perkembangan tanaman. Aplikasi mulsa erat kaitannya dengan suhu tanah yang merupakan salah satu dari fungsi mulsa sendiri. Suhu tanah dalam penelitian ini tidak dipengaruhi oleh mulsa organik dan jumlah populasi tanaman. Tabel 1 menunjukkan rata-rata suhu tanah akibat pemberian mulsa organik dan populasi tanaman berkisar antara 35,25 - 36,25 ㄷ․ Pemberian mulsa dan populasi tanaman belum mampu menahan kondisi lingkungan tanah. Hal ini disebabkan karena dosis mulsa yang masih rendah sehingga belum optimal untuk menjaga kondis iklim mikro. Menurut Wisudawati et al. (2016) mulsa mempengaruhi kondisi iklim mikro dalam tanah seperti kadar air tanah dan suhu tanah. Suhu tanah yang stabil dan optimum mampu meningkatkan aktivitas mikroorganisme untuk mengurai bahan organik menjadi unsur yang tersedia bagi tanaman. Menurut Sen an Kumar (2012) peningkatan mikroorganisme mampu merangsar pertumbuhan tanaman dengan menyediakan nutrisi di daerah rhizosfer sebagai hasil simbiosis. Hasil penelitian menunjukkan bahwa kombinasi tidak berpengaruh nyata terhadap suhu tanah.

\section{KESIMPULAN}

Pemberian mulsa jerami pada 2 tanaman per lubang mampu meningkatkan tinggi tanaman dan jumlah cabang produktif. Pemberian mulsa jerami pada 2 tanaman belum mampu meningkatkan hasil tanaman kacang hijau secara signifikan. Hasil kacang hijau pada penelitian ini sebesar 1,54 ton/ha.

\section{SARAN}

Saran yang diberikan untuk penelitian ini adalah penggunaan jenis mulsa dan pengaturan jumlah populasi tanaman belum mampu meningkatkan hasil kacang hijau. Sebaiknya penggunaan mulsa organik didasarkan pada tingkat ketebalannya.

\section{DAFTAR PUSTAKA}

Altland J, Boldt JK, Krause CC. 2016. Rice hull mulch affects germination of bittercress and creeping woodsorrel in container plant culture. Am J Plant Sci 7(1): 2359-2375.

Balitkabi. 2010. Teknologi produksi kacang hijau. Malang (ID): Kementrian Pertanian Republik Indonesia.

Balitkabi. 2012. Produksi kacang hijau. Malang (ID): Kementrian Pertanian Republik Indonesia.

Bandani M, Mobbaser HR, Sirusmehr A. 2014. Effect of organic fertilizer on length of pod, biological yield and number of seeds per pod in mungbean (Vigna radiata L.). Int Res J Basic Appl Sci 8(7): 763-766.

Barnard A, CAlitz FJ. 2011. The effect of poor quality seed and various levels of grading factors on the germination, emergence and yield of wheat. S Afr J Plant Soil 28(1): 23-33. 
Bunkar D, Singh RK, Choudhary HR, Jat AL. 2013. Effect of row spacing and mulching on growth and production of Mungbean (Vigna radiate L. Wilczek) in guava (Psidium guajava L.). J Ecol Environ Sci 31(1): 160-163.

Canci H, Toker C. 2014. Yield components in mung bean [Vigna radiata (L.) Wilczek]. Turk J Field Crops 19(2): 258-261.

Chaturverdi GS, Anggarwal PK, Sinha SK. 1980. Growth and yield of determinate and indeterminate cowpeas in dryland agriculture. J Agric Sci Camb 94(1): 137-144.

Febriyono R, Susilowati YE, Suprapto A. 2017. Peningkatan hasil tanaman kangkung darat (Ipomoea reptans, L.) melalui perlakuan jarak tanam dan jumlah tanaman per lubang tanam. J IImu Pertanian Tropika dan Subtropika 2(1): 22-27.

Gardner FP, Pearce RB, Mitchell RL. 1991. Fisiologi Tanaman Budidaya. Jakarta (ID): UI Press.

Hamdani JS. 2009. Pengaruh jenis mulsa terhadap pertumbuhan dan hasil tiga kultivar kentang (Solanum tuberosum L.) yang ditanam di dataran medium. J Agron. Indonesia 37 (1) : $14-20$.

Iswanto R. 2017. Vima2, varietas baru kacang hijau, alternative untuk mengatasi lahan bera. Malang (ID): Balai Penelitian Aneka Kacang dan Umbi.

Karamina H, Fikrinda W, Murti AT. 2017. Kompleksitas pengaruh temperature dan kelembaban tanah terhadap nilai $\mathrm{pH}$ tanah di perkebunan jambu biji varietas kristal (Psidium guajava I.) Bumiaji, Kota Batu. J Kutivasi 16(3): 430-434.

Kumar S, Jakhar DS, Singh R. 2018. Growth and yield response of mung bean (Vigna radiata L.) in different of potassium. Acta J Sci Agr 2(6): 23-25.

Midmore DJ. 1993. The use of mulch for potato in the hot tropics. Circular 2(1):1-2.

Modal MJ, Fakir MS, Juraimi AS et al. 2011. Effects of flowering behavior and pod maturity synchrony on yield of mungbean [Vigna radiata (L.) Wilczek]. Austr J Crop Sci 5(8): 945-953

Noorhadi dan Sudadi. 2003. Kajian pemberian air dan mulsa terhadap iklim mikro pada tanaman cabai di tanah entisol. J IImu Tanah dan Lingkungan 4(1): 41-49.

Pandey S, Singh J,Maurya IB. 2015. Effect of black polythene mulch on growth and yield on winter dawn strawberry (Fragaria $x$ ananassa) by improving root zone temperature. Indian J Agr Sci 85(9): 12191122.

Pott HC, Duangprata J, Hairston WG, Delouche JC. 1978. Some influence of hardseedness on soybean seed quality. J Crops Sci 18(2): 221-224.

Rahmianna AA, Purnomo J, Harnowo D. 2015. Pemanfaatan biji keriput kacang tanah sebagai benih. Iptek Tanaman Pangan 10(2): 57-67.
Ramadiana S. 2011. The application of rice hull mulch and potassium nitrate on growth and yield of kailan (Brassica oleraceae var. long leaf). J Trop Soils 16(2): 145-150.

Rasyid H. 2013. Peningkatan produksi dan mutu benih kedelai varietas hitam unggul nasional sebagai fungsi jarak tanam dan pemberian dosis pupuk P. J Gamma 8(2): 46-63.

Salisbury FB. 1969. In the introduction of flowering. Ithaca: Cornell Universuty Press.

Sen S, Kumar V. 2012. The effect of different soil amendments on growth of mung bean (Vigna radiate L.) in coal mine overburden dumps. Int $\mathbf{J}$ Emerging Technol and Adv Eng 2(12): 264-270.

Sriphadet S, Lambrides CJ, Srinivers P. 2007. Inheritance of Agronomic Traits and Their Interrelationship in Mungbean (Vigna radiate (L.) Wilczek). J Crop Sci Biotech 10 (4) : 249-256.

Sunghening W. 2012. Pengaruh mulsa organik terhadap pertumbuhan dan hasil tiga varieta kacang hijau (Vigna radiata L. Wilczek) di lahan pasir pantai bugel, Kulon Progo. J Pertanian 9(1): 137-141.

Suprapto HS. 2007. Bertanam Kedelai. Jakarta (ID): Penebar Swadaya.

Susilo J, Ardian, Ariani E. 2015. Pengaruh jumlah bibit per lubang tanam dan dosis pupuk N, P dan K terhadap pertumbuhan dan produksi padi sawah (Oryza sativa I.) dengan metode SRI. Jom Faperta 2(1): 1-15.

Wasala SK, Fernando W, Narasinghe. 2011. Hardseededness of local mungbean (Vigna radiata) varieties. Trop J Agr Res Ext 14 (1): 5-6.

Wisudawati D, Anshar M, Lapanjang I. 2016. Pengaruh jenis mulsa terhadap pertumbuhan dan hasil bawang merah (Allium ascalonicum Var. Lembah Palu) yang diberi sungkup. J Agrotekbis 4(2): 126 133.

Wiwara S, Tohari, Fajar. 2013. Pengaruh mulsa organik terhadap pertumbuhan dan hasil tiga kultivar kacang hijau (Vigna radiata L. Wilcek) di lahan pasir pantai Bugel, Kulon Progo. J IImu Tanah dan Lingkungan 4(8): 21-29.

Zecchinelli R. 2009. The influence of seed quality on crop productivity. ISTA. World Seed Conference. 